\title{
Consistent prevalence of inadequate micronutrient intakes across six years of second-year medical school students
}

\author{
Lynn Seabolt, Taren B. Spence, Heidi J. Silver ${ }^{*}$ \\ Department of Medicine, Division of Gastroenterology, School of Medicine, Vanderbilt University, Nashville, USA; \\ *Corresponding Author: Heidi.j.silver@,vanderbilt.edu
}

Received 8 February 2012; revised 20 March 2012; accepted 17 April 2012

\section{ABSTRACT}

Background: The dietary behaviors of physiccians and medical students are strongly associated with their nutrition counseling practices. Little research to date describes their dietary intakes and no recent studies have assessed the adequacy of their micronutrient intakes. As micronutrient imbalances are associated with a variety of chronic diseases, public guidelines target increasing dietary nutrient density. The purpose of this study was to identify micronutrient imbalances in the diets of medical students and determine whether intakes are becoming more compliant with dietary guidelines over time. Methods: From 2000 to 2006, 409 second-year Vanderbilt University medical students completed the Block Brief 2000 food frequency questionnaire prior to the required "Introduction to Clinical Nutrition" course. Nutrient data were compared to Dietary Reference Intake values. Results: Dietary intakes of male students were consistently inadequate for vitamin E, vitamin D, calcium, magnesium and potassium across the six cohorts. Despite a significant increase over time in the number of vegetable servings consumed, the intakes of female students revealed the same inadequacies, as well as inadequate folate and iron intakes. Multivitamin and multimineral supplementation, consumed regularly by $51 \%$ of students, closed the gap in meeting estimated micronutrient requirements, except vitamin E. Conclusions: These data can be used to inform the content of nutrition interventions for medical students focused on making optimal food selection choices as well as the content of nutrition education in the medical school curriculum. It is important to enhance medical students' preparedness as fu- ture health care providers - not only to serve as role models for healthy dietary behaviors, but also to better recognize the nutrition needs of their future patients.

Keywords: Micronutrients; Students; Physicians; Dietary Intake

\section{INTRODUCTION}

Healthy People 2000, 2010 and 2020 objectives include increasing the proportion of patients who routinely receive nutrition assessments and the proportion of physician office visits that include nutrition/diet education and counseling [1]. These objectives stem from the compelling body of evidence elucidating the importance of dietary intakes for health maintenance and chronic disease risk reduction. Shifting the focus of health care delivery from treatment to prevention requires a parallel adjustment in the content of nutrition education in medical schools and in the health behaviors of practicing physicians. In fact, studies show that physicians and medical students' awareness of their dietary behaviors and knowledge of their nutrient imbalances impacts their nutrition counseling practices and provision of appropriate nutriation care to patients [2-5]. Not only are physicians and medical students who consume more fruits and vegetables more likely to provide nutrition counseling, they also consider their advice to be more believable $[4,6]$. Further, physicians who share their own beneficial diet and exercise behaviors during patient counseling are perceived by patients to be more credible and more motivating [7]. These findings underscore the potential role of future physicians as models for healthy behaviors and the likelihood that patients will become more engaged in dietary behavior change when recommended by physicians who practice what they counsel.

Although several studies have published data on the nutrition knowledge [8-10], adequacy of nutrition train- 
ing [11-17], and nutrition counseling practices [18,19] of US physicians and medical students, few investigations describe their dietary intakes. Using 24-hour recall, Heimburger and colleagues [20] reported a significant decline in total fat intake along with a trend for decreasing saturated fat intake in first-year medical students attending the University of Alabama from 1989 to 1992. Similarly, Banks and colleagues [21] observed a decline in total fat intake during medical school in students who completed repeated food frequency questionnaires (FFQ). In a more recent investigation, Spencer and colleagues [22] showed that while medical students who reported being vegetarians consumed significantly more fruit, vegetable and dairy servings daily than non-vegetarians, average fruit and vegetable consumption of all students was lower than dietary guidelines and declined during medical school.

Interestingly, little attention has been paid to the micronutrient intakes of medical students. Yet, national data indicate that most Americans consume inadequate amounts of several micronutrients, especially vitamin A, vitamin $\mathrm{C}$, vitamin $\mathrm{E}$, calcium, magnesium and potassium [23]. These inadequacies are concerning as suboptimal micronutrient intakes are associated with a wide range of health conditions and chronic disease states [24-38]. Consequently, the US Departments of Health and Human Services and Agriculture in the Dietary Guidelines for Americans, 2010 emphasize increasing the micronutrient density of the diet by consuming greater amounts of foods rich in vitamins, minerals, and fiber, while reducing consumption of energy-dense foods [23]. It is expected that physicians will participate in implementing public adherence to these recommendations.

As prior investigation of the micronutrient adequacy of physicians or medical students' diets is scant, the main objective of this study was to identify micronutrient imbalances in the diets of current US medical students and determine whether intakes are becoming more compliant with dietary guidelines over time. Although often overlooked by health care providers, the wide prevalence of micronutrient inadequacies in the general population indicates that regardless of healthcare setting future physicians will interact with patients at risk. Hence, it is necessary for medical students to become well-prepared to incorporate appropriate nutrition counseling into their future clinical practices and be able to recognize patients in need of referral to registered dietitians. Having specific information about their own diet and nutrient intakes may be an indicator of their preparedness for meeting the Healthy People objectives to provide relevant nutrition services and it may also provide insight into their nutrition education needs.

\section{METHODS}

\subsection{Administration of Food Frequency Questionnaire}

Beginning December 2000 and ending December 2006, all second year Vanderbilt University School of Medicine (VUSM) students registered for the required spring semester "Introduction to Clinical Nutrition" course received a Block Brief 2000 FFQ (Block Dietary Data Systems, Berkeley, CA) in their campus mailboxes four weeks prior to the beginning of the semester. Written instructions were provided describing how to complete the FFQ and use a food serving size poster (2D Food Portion Visual, Nutrition Consulting Enterprises, Framingham, Mass.) to estimate portion sizes. Students were instructed to return the FFQ within two weeks in the addressed stamped envelopes provided. Questionnaires were reviewed for completeness upon return. The primary purpose of the FFQ exercise in the context of the Introduction to Clinical Nutrition course was to familiarize students with a common method of dietary assessment, to promote reflection on personal dietary habits and food choices, and to identify nutrient imbalances. The study conformed to Health Insurance Portability and Accountability Act guidelines and was deemed exempt by the Vanderbilt University Institutional Review Board.

\subsection{Food Frequency Questionnaire Data}

The Block Brief 2000 FFQ [39] is a practical and easily administered instrument that contains a food list of 70 items designed to assess usual food and beverage consumption over the past year. This instrument was also chosen because the food list and portion sizes were identified as the largest contributors to nutrient intakes in the average American diet by the Third National Health and Nutrition Examination Survey (NHANES III) dietary recall data [39]. In addition, the nutrient database was developed from the USDA Nutrient Database for Standard Reference [40]. Further, it has been validated against three- and seven-day food records in males and females [39]. Frequency of consumption of the 70 foods was reported at nine levels of intake from "never" to "every day". In addition, there were seven dietary behavior queries on food preparation methods and fat intake, one query on fiber intake, and 13 queries on vitamin and mineral intakes. Seven demographic variables were included to describe gender, age, height, weight, smoker status, pregnancy status and supplement use.

\subsection{Data Analysis}

Energy and nutrient intake data were analyzed using SPSS (version 15.0, 2009, SPSS Inc., Chicago, IL). Descriptive statistics were conducted for all variables. $\mathrm{Nu}-$ 
trient data were excluded from further analyses if total daily energy intake values were out of the range of the normal distribution curve, i.e., $<600 \mathrm{kcal}(\mathrm{n}=8)$ or $>4000 \mathrm{kcal}(\mathrm{n}=2)$. To assess the adequacy of energy, protein and fiber intakes, paired two-sample $t$ tests were performed for males and females separately to compare intakes to nutrient-based reference values using the Acceptable Macronutrient Distribution Ranges [41] for young adults aged 19 - 30 years. Likewise, micronutrient intakes were compared to the Estimated Average Requirement (EAR) or Adequate Intake (AI) value as defined by the Institute of Medicine Food and Nutrition Board in the Dietary Reference Intakes [42]. To compare differences in intakes over time, general linear models (GLM) were conducted for univariate analyses of nutriaent outcome variables with school year and gender as fixed effects (interaction effect of gender with year in study). Energy (calories) was included in the GLM models as a covariate to control for the relationship between energy and nutrient intakes. Nutrient outcome variables were analyzed from food and from dietary supplements. A conservative type I error rate of $\leq 0.01$ was maintained for tests of statistical significance. Values are expressed as means $\pm \mathrm{SD}$.

\section{RESULTS AND DISCUSION}

Overall, 409 of 627 (65\%) eligible VUSM students returned their FFQ within the two-week data collection period. No significant differences were detected by year for demographic variables. The self-reported ethnic makeup of students was 74\% Caucasian, 19\% Asian, 5\% African American and 2\% Hispanic. Fifty-one percent were male and the mean age was $24 \pm 2$ years. The mean BMI for males was $23.8 \pm 2.9 \mathrm{~kg} / \mathrm{m}^{2}$ and $21.0 \pm 2.3 \mathrm{~kg} / \mathrm{m}^{2}$ for females. Only two students reported current smoking and no females reported pregnancy. Sixteen (4\%) students reported consuming no meat, chicken or fish.

Over the six-year period of student cohorts, no significant changes in the amounts of energy or macronutrients being consumed were detected $(P=0.683)$. Average reported daily energy intakes was $1825 \pm 580 \mathrm{kcal} /$ day for males and $1388 \pm 540 \mathrm{kcal} /$ day for females. Dietary macronutrient composition averaged $31 \% \pm 6 \%$ fat, $51 \% \pm 8 \%$ carbohydrate and $18 \% \pm 4 \%$ protein for males and $30 \% \pm 6 \%$ fat, $53 \% \pm 7 \%$ carbohydrate and $17 \% \pm$ $3 \%$ protein for females. Energy, protein and total fiber intakes were significantly less than estimated requirements for males and females in all years $(P \mathrm{~s}<0.001)$. In contrast, saturated fat intakes (males: $22 \% \pm 10 \%$, females: $17 \% \pm 9 \%$ ) were significantly greater than the current recommendation of $<10 \%$ total calories. Notably, these findings are inconsistent with advances in national recommendations for healthful eating as depicted in the
Dietary Guidelines for Americans, 2005 or the US Department of Agriculture MyPyramid Food Guidance System $[43,44]$.

As reported energy intakes were low, it follows that average daily consumption from key food groups was also low (Figures 1 and 2). Overall, male students reported consuming $2.4 \pm 1.6$ meat servings/d, $2.0 \pm 1.2$ dairy servings/d, $5.7 \pm 2.1$ grain servings $/ \mathrm{d}, 1.4 \pm 0.8$ fruit servings/d, $2.7 \pm 1.6$ vegetable servings/d and $1.6 \pm$ 1.0 fat servings/d. Female students reported consuming $1.6 \pm 0.8$ meat servings/d, $1.6 \pm 0.9$ dairy servings/d, 4.1 \pm 1.9 grain servings/d, $1.4 \pm 0.7$ fruit servings $/ \mathrm{d}, 2.8 \pm$ 1.8 vegetable servings/d and $1.6 \pm 1.1$ fat servings $/ \mathrm{d}$. The only food group for which there was a significant increase in the number of servings consumed across the cohorts was the vegetable group, increasing from $2.6 \pm$ 1.5 to $3.3 \pm 2.1$ servings $/ \mathrm{d}(P=0.014)$ across female cohorts.

Food and beverage intakes were consistently high in sodium, phosphorus and vitamin A (Tables 1). Overall, $90.7 \%$ of males and $63.6 \%$ of females reported consuming more sodium than the recommended AI. Sodium intakes were mainly from regular consumption of lunch meats, chips, pizza and French fries. In addition, 97\% of males and $90.3 \%$ of females reported consuming more phosphorus than the EAR, primarily from consuming milk, cheese and soft drinks.

Simultaneously, males' food intakes were consistently inadequate in vitamin $\mathrm{E}$, vitamin $\mathrm{D}$, calcium, magnesium and potassium (Table 1(a)). Overall, $87.3 \%$ of males reported consuming foods that provided less than the EAR for vitamin $\mathrm{E}$. The main sources of vitamin $\mathrm{E}$ intakes

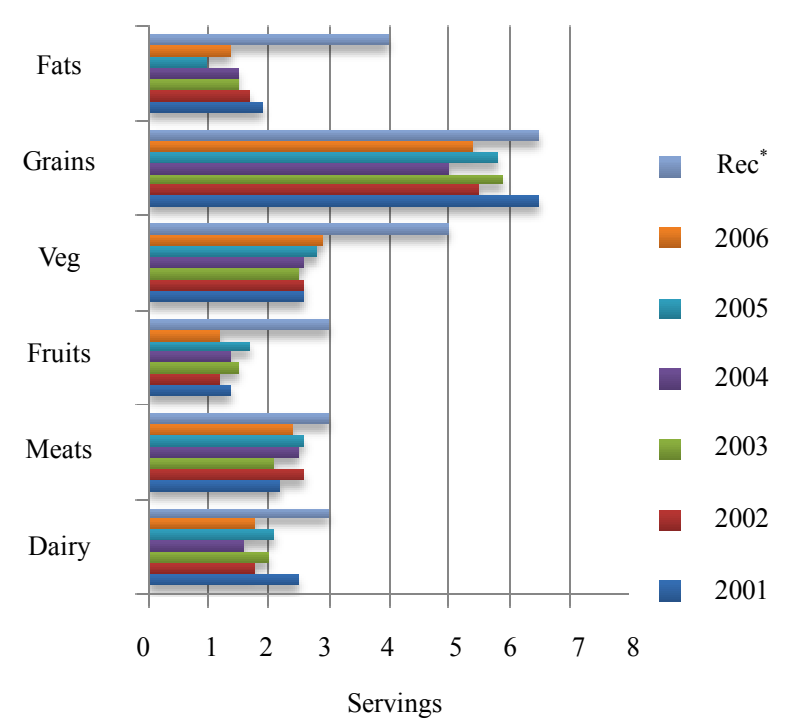

Figure 1. Average reported number of food group servings consumed each year by male medical students in comparison to MyPyramid recommendations $\left(\operatorname{Rec}^{*}\right)$. 


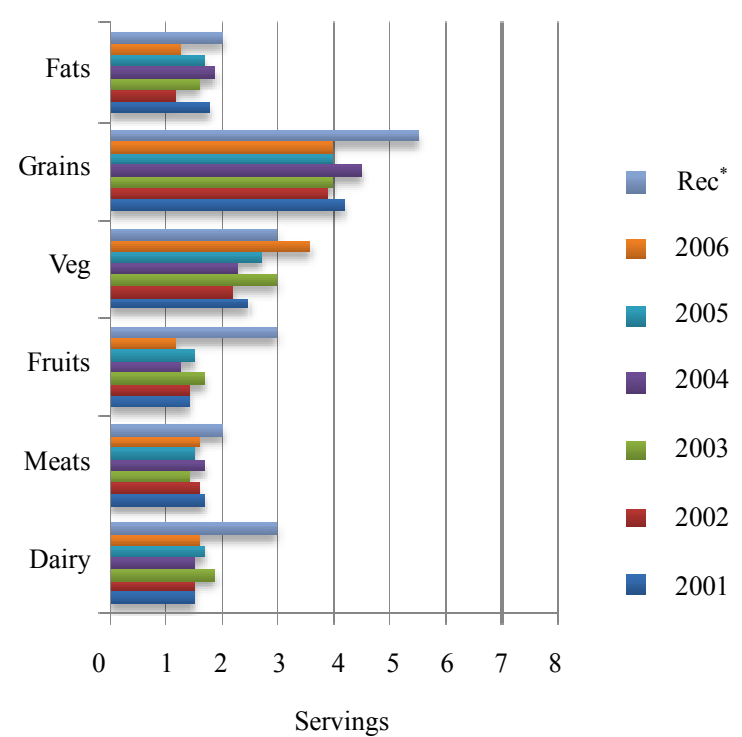

Figure 2. Average reported number of food group servings consumed each year by female medical students in comparison to MyPyramid recommendations $\left(\operatorname{Rec}^{*}\right)$.

were derived from consuming chips, salad dressing and peanut butter. Although males reported regular consumption of milk, cheese, yogurt and ice cream, $61 \%$ of males had intakes that provided less than the AI for calcium and $61.8 \%$ had intakes that provided less than the AI for vitamin D. Similarly, $62.7 \%$ of males consumed foods that provided less than the EAR for magnesium, derived primarily from vegetable and legume intakes. As daily fruit servings were low (Figure 1(a)), primarily from limited orange juice, apple and banana intakes, 94.6\% of males consumed less than the AI for potassium.

For females, food intakes consistently provided inadequate amounts of folate, vitamin $\mathrm{D}$, vitamin $\mathrm{E}$, calcium, potassium, magnesium and iron (Table 1(b)). Overall, $51.8 \%$ of females had intakes that provided less than the EAR for folate despite daily consumption of eggs or (fortified) cereals. As displayed in Figure 1(b), females reported consuming a variety of dairy products (i.e., milk, cheese, yogurt and ice cream), 73.8\% had intakes that provided less than the AI for calcium and 73.3\% had intakes providing less than the AI for vitamin D. Similarly to male students, females derived most of their vitamin $E$ intakes from consuming salad dressing and peanut butter, but $95.4 \%$ had intakes providing less than the EAR. Almost all (99\%) females' intakes provided less than the AI for potassium and $45.1 \%$ consumed less than the EAR for magnesium. In addition, $25.6 \%$ of females reported intakes that provided less than the EAR for iron, although the majority of iron intakes were from heme protein sources (i.e., chicken, hamburger, other beef and pork).

The finding of high sodium, phosphorus and vitamin
A intakes in the setting of insufficient intakes of other key micronutrients emphasizes the need for medical students to learn how to optimize the nutrient density of their daily intakes. Certain simple additions or substitutions could be recommended that are likely to yield significant improvements. For example, substituting foods from the legumes group (i.e., dry beans, peas and lentils) as protein sources in main meals and adding various types of nuts and seeds as between-meal snacks would be a relatively easy strategy to better balance dietary intakes and a potential solution to improving the intakes of vitamin $\mathrm{E}$ as well as folate, iron, calcium, magnesium, potassium, fiber and protein [45]. Students could also be taught to make intentional choices regarding their staple foods such as selecting calcium-fortified orange juice and cereals that are folate-fortified and high in fiber.

While foods and beverages are the preferred sources of micronutrient intakes because of the variety, synergy and bioavailability of nutrients provided, the present data suggest that inadequate total food intake may be a problem in this population. In light of this concern, multivitamin multimineral (MVM) supplementation may be another strategy to close the gap between intakes and requirements [46]. Consistent with prior literature [47], the present data showed that about half $(51 \%)$ of students in each cohort reported taking MVM regularly for an average of three years. For supplement users, total folate, vitamin $\mathrm{E}$, vitamin $\mathrm{D}$, calcium, magnesium and iron intakes were significantly greater than non-supplement users (all $P$ s $<0.001$ ). Thus, supplement use increased total micronutrient intakes to levels that met the respective nutrient reference values, except for vitamin $\mathrm{E}$ which remained deficient in $14 \%-28 \%$ of students in each cohort.

In interpreting these data, some limitations should be noted. The data were not collected from a random sample but rather a convenience sample of medical students.

While it is possible the findings might differ in the group of students who did not respond to the survey, the demographics of the responders are consistent with a recent nationally representative survey [48] and the findings from these students agree with larger and more representative investigation of medical students' energy and nutrient intakes [21]. Secondly, like most methods of dietary assessment, all of the data are self-reported; it is possible that using a reduced-length FFQ allows underor over-reporting of energy and nutrient intakes by as much as $20 \%$ [50]. However, the actual reporting error rate in medical students overall and those sampled herein is unknown. Thus, it would not be possible to reliably correct for potential error rate in the present study [49]. Notably, the Block FFQs are widely used, have been tested in numerous populations, and the data collected are strongly associated with reference measures of intakes 
Table 1. (a) Average micronutrient intakes from reported food and beverage intakes of male second year medical students across six years; (b) Average micronutrient intakes from reported food and beverage intakes of female second year medical students across six years.

(a)

\begin{tabular}{|c|c|c|c|c|c|c|c|}
\hline & Source* & 2001 & 2002 & 2003 & 2004 & 2005 & 2006 \\
\hline & & $\mathrm{n}=38$ & $\mathrm{n}=33$ & $\mathrm{n}=31$ & $\mathrm{n}=33$ & $\mathrm{n}=30$ & $\mathrm{n}=38$ \\
\hline \multicolumn{8}{|l|}{ Vitamins } \\
\hline Thiamin (mg) & 1.2 & $1.9 \pm 0.6$ & $1.2 \pm 0.5$ & $1.8 \pm 0.6$ & $1.5 \pm 0.6$ & $1.9 \pm 0.7$ & $1.5 \pm 0.5$ \\
\hline Riboflavin (mg) & 1.3 & $2.3 \pm 0.9$ & $1.8 \pm 0.6$ & $2.0 \pm 0.8$ & $1.8 \pm 0.7$ & $2.2 \pm 0.9$ & $1.8 \pm 0.7$ \\
\hline Niacin (mg) & 16 & $23.2 \pm 8.6$ & $20.1 \pm 8.2$ & $20.9 \pm 6.9$ & $20.1 \pm 8.0$ & $24.0 \pm 8.8$ & $20.4 \pm 8.8$ \\
\hline Folate (mcg) & 400 & $455.4 \pm 159.2$ & $379.9 \pm 127.7$ & $429.8 \pm 154.6$ & $380.6 \pm 135.0$ & $451.8 \pm 185.5$ & $381.7 \pm 131.6$ \\
\hline Vit B6 (mg) & 1.3 & $2.2 \pm 0.8$ & $1.9 \pm 0.7$ & $2.1 \pm 0.7$ & $1.9 \pm 0.7$ & $2.3 \pm 0.9$ & $1.9 \pm 0.7$ \\
\hline Vit B12 (ug) & 2.4 & $6.2 \pm 3.5$ & $5.2 \pm 2.5$ & $5.5 \pm 4.1$ & $4.8 \pm 2.6$ & $7.2 \pm 4.7$ & $4.8 \pm 2.4$ \\
\hline Vit A (IU) & 3000 & $10635.4 \pm 7469.9$ & $9236.0 \pm 7295.7$ & $10800.4 \pm 5798.4$ & $10102.6 \pm 7233.9$ & $10936.6 \pm 5351.5$ & $10872.7 \pm 7952.8$ \\
\hline Vit C (mg) & 90 & $150.8 \pm 78.6$ & $110.0 \pm 51.0$ & $135.8 \pm 67.6$ & $109.0 \pm 57.6$ & $138.8 \pm 74.6$ & $101.0 \pm 62.9$ \\
\hline Vit D (IU) & 200 & $226.2 \pm 159.2$ & $171.6 \pm 120.2$ & $195.7 \pm 163.6$ & $161.0 \pm 116.2$ & $236.1 \pm 159.3$ & $175.6 \pm 112.0$ \\
\hline Vit E (mg) & 15 & $7.3 \pm 5.0$ & $6.1 \pm 2.1$ & $6.9 \pm 4.9$ & $6.1 \pm 2.6$ & $8.5 \pm 6.6$ & $5.9 \pm 2.5$ \\
\hline Vit K (ug) & 120 & $115.4 \pm 83.0$ & $126.8 \pm 110.0$ & $166.3 \pm 132.1$ & $145.0 \pm 127.5$ & $169.7 \pm 127.4$ & $169.9 \pm 125.2$ \\
\hline \multicolumn{8}{|l|}{ Minerals } \\
\hline Sodium (mg) & 1500 & $2647.2 \pm 847.7$ & $2548.4 \pm 854.1$ & $2447.2 \pm 854.2$ & $2410.3 \pm 1012.4$ & $2735.7 \pm 894.2$ & $2360.4 \pm 836.4$ \\
\hline Phosphorus (mg) & 700 & $1437.8 \pm 479.4$ & $1265.1 \pm 413.4$ & $1317.8 \pm 483.1$ & $1224.4 \pm 475.8$ & $1408.9 \pm 483.7$ & $1248.8 \pm 419.3$ \\
\hline Calcium (mg) & 1000 & $1098.4 \pm 412.1$ & $857.8 \pm 350.1$ & $950.3 \pm 458.5$ & $808.5 \pm 364.4$ & $960.4 \pm 472.5$ & $843.6 \pm 337.9$ \\
\hline Magnesium (mg) & 400 & $317.1 \pm 102.6$ & $275.2 \pm 87.0$ & $307.9 \pm 95.0$ & $294.7 \pm 113.7$ & $325.5 \pm 120.7$ & $291.6 \pm 100.2$ \\
\hline Potassium (mg) & 4700 & $3219.2 \pm 970.1$ & $2766.0 \pm 973.2$ & $3032.6 \pm 803.0$ & $2878.4 \pm 1153.4$ & $3252.3 \pm 1157.9$ & $2763.9 \pm 925.1$ \\
\hline Iron (mg) & 8 & $18.1 \pm 7.3$ & $14.9 \pm 5.9$ & $15.9 \pm 6.4$ & $14.2 \pm 5.3$ & $18.1 \pm 7.9$ & $14.5 \pm 5.9$ \\
\hline Zinc (mg) & 11 & $12.5 \pm 5.9$ & $10.7 \pm 4.3$ & $11.5 \pm 4.9$ & $11.2 \pm 5.0$ & $14.0 \pm 6.2$ & $11.1 \pm 4.6$ \\
\hline
\end{tabular}

\section{Antioxidants}

Carotene (ug)

$5131.5 \pm 4368.4 \quad 4694.6 \pm 4316.2 \quad 5553.4 \pm 3492.5$

$5256.5 \pm 4233.1$

$5526.6 \pm 3143.8$

$5668.2 \pm 4700.5$

$\alpha$-carotene (ug)

$950.8 \pm 1085.3$

$682.5 \pm 755.4$

$832.3 \pm 717.3$

$725.0 \pm 900.1$

$729.2 \pm 628.5$

$866.6 \pm 1041.5$

$\beta$-carotene (ug)

$3558.7 \pm 2761.9$

$3494.9 \pm 3150.0$

$4123.3 \pm 2583.2$

$4097.2 \pm 3273.0$

$4400.1 \pm 2549.4$

$4249.4 \pm 3318.0$

Cryptoxanthin (ug)

$230.9 \pm 176.1$

$129.9 \pm 116.6$

$177.9 \pm 173.0$

$148.6 \pm 121.1$

$187.4 \pm 152.9$

$117.9 \pm 145.9$

Lutein (ug)

Lycopene (ug)

$1579.7 \pm 1177.3 \quad 1501.8 \pm 1446.2 \quad 2231.0 \pm 2473.7$

$2023.6 \pm 2272.2$

$2319.3 \pm 2208.9$

$2276.5 \pm 1879.5$

$9702.1 \pm 5226.3 \quad 8896.4 \pm 4937.5 \quad 7957.2 \pm 5081.6$

$6811.3 \pm 4195.0 \quad 7472.5 \pm 4407.3$

$6148.7 \pm 4066.7$

*Recommended Dietary Allowance or Adequate Intake value for men age 19 - 30 years.

Values are means $\pm \mathrm{SD}$. 
(b)

\begin{tabular}{|c|c|c|c|c|c|c|c|}
\hline & Source* & 2001 & 2002 & 2003 & 2004 & 2005 & 2006 \\
\hline & & $\mathrm{n}=30$ & $\mathrm{n}=18$ & $\mathrm{n}=31$ & $\mathrm{n}=33$ & $\mathrm{n}=45$ & $\mathrm{n}=37$ \\
\hline \multicolumn{8}{|l|}{ Vitamins } \\
\hline Thiamin (mg) & 1.1 & $1.2 \pm 0.5$ & $1.3 \pm 0.6$ & $1.3 \pm 0.5$ & $1.4 \pm 0.7$ & $1.2 \pm 0.4$ & $1.1 \pm 0.4$ \\
\hline Riboflavin (mg) & 1.1 & $1.5 \pm 0.6$ & $1.5 \pm 0.8$ & $1.7 \pm 0.7$ & $1.6 \pm 0.9$ & $1.6 \pm 0.6$ & $1.5 \pm 0.6$ \\
\hline Niacin (mg) & 14 & $15.2 \pm 8.0$ & $16.3 \pm 8.8$ & $15.5 \pm 6.6$ & $16.5 \pm 8.4$ & $15.5 \pm 6.6$ & $14.9 \pm 7.3$ \\
\hline Folate (mcg) & 400 & $331.5 \pm 130.9$ & $319.6 \pm 163.4$ & $346.9 \pm 139.2$ & $353.1 \pm 194.2$ & $338.2 \pm 128.6$ & $351.3 \pm 143.2$ \\
\hline Vit B6 (mg) & 1.3 & $1.5 \pm 0.5$ & $1.6 \pm 0.9$ & $1.7 \pm 0.7$ & $1.6 \pm 0.8$ & $1.6 \pm 0.6$ & $1.5 \pm 0.6$ \\
\hline Vit B12 (ug) & 2.4 & $4.6 \pm 3.8$ & $3.5 \pm 2.9$ & $4.3 \pm 2.9$ & $4.2 \pm 3.2$ & $3.4 \pm 2.1$ & $3.6 \pm 2.6$ \\
\hline Vit A (IU) & 2333 & $9918.7 \pm 9218.6$ & $10970.4 \pm 10798.7$ & $12688.3 \pm 9859.2$ & $8479.7 \pm 6009.8$ & $12427.8 \pm 8680.7$ & $14097.3 \pm 11057.7$ \\
\hline Vit C (mg) & 75 & $100.4 \pm 51.3$ & $102.9 \pm 63.3$ & $111.6 \pm 46.2$ & $103.3 \pm 58.6$ & $100.4 \pm 52.6$ & $94.7 \pm 38.6$ \\
\hline Vit D (IU) & 200 & $139.6 \pm 100.7$ & $139.4 \pm 94.9$ & $165.9 \pm 113.8$ & $127.5 \pm 95.2$ & $154.7 \pm 90.7$ & $133.1 \pm 130.3$ \\
\hline Vit E (mg) & 15 & $5.7 \pm 2.4$ & $5.4 \pm 6.2$ & $6.4 \pm 5.2$ & $7.1 \pm 6.7$ & $5.5 \pm 2.8$ & $5.3 \pm 2.0$ \\
\hline Vit K (ug) & 90 & $123.6 \pm 99.3$ & $106.1 \pm 77.9$ & $171.6 \pm 153.5$ & $110.7 \pm 91.6$ & $194.3 \pm 181.7$ & $263.3 \pm 277.0$ \\
\hline \multicolumn{8}{|l|}{ Minerals } \\
\hline Sodium (mg) & 1500 & $1839.5 \pm 895.5$ & $1725.1 \pm 634.9$ & $1921.2 \pm 632.1$ & $1985.0 \pm 899.0$ & $2004.2 \pm 760.3$ & $1897.6 \pm 797.9$ \\
\hline Phosphorus (mg) & 700 & $983.6 \pm 406.7$ & $942.1 \pm 294.8$ & $1058.9 \pm 353.7$ & $998.4 \pm 437.5$ & $1036.7 \pm 350.9$ & $1036.6 \pm 385.8$ \\
\hline Calcium (mg) & 1000 & $716.6 \pm 311.2$ & $700.1 \pm 284.3$ & $857.8 \pm 320.2$ & $724.6 \pm 396.8$ & $804.4 \pm 319.3$ & $784.5 \pm 318.9$ \\
\hline Magnesium (mg) & 310 & $237.5 \pm 99.7$ & $213.6 \pm 69.8$ & $241.1 \pm 69.1$ & $227.6 \pm 102.5$ & $250.2 \pm 85.9$ & $268.8 \pm 103.9$ \\
\hline Potassium (mg) & 4700 & $2350.4 \pm 855.4$ & $2215.3 \pm 749.5$ & $2495.6 \pm 612.4$ & $2244.3 \pm 858.1$ & $2450.0 \pm 824.5$ & $2476.1 \pm 888.6$ \\
\hline Iron (mg) & 18 & $11.4 \pm 4.9$ & $12.3 \pm 7.5$ & $12.9 \pm 5.9$ & $13.1 \pm 7.6$ & $12.3 \pm 5.6$ & $11.4 \pm 5.1$ \\
\hline Zinc (mg) & 8 & $8.2 \pm 4.1$ & $8.8 \pm 5.3$ & $9.0 \pm 4.7$ & $9.4 \pm 5.8$ & $8.9 \pm 3.6$ & $8.5 \pm 3.7$ \\
\hline \multicolumn{8}{|l|}{ Antioxidants } \\
\hline Carotene (ug) & & $5252.8 \pm 5559.7$ & $5889.4 \pm 6167.1$ & $6747.3 \pm 5882.5$ & $4326.8 \pm 3536.8$ & $6697.8 \pm 5195.3$ & $7784.9 \pm 6658.7$ \\
\hline$\alpha$-carotene (ug) & & $933.7 \pm 1285.5$ & $1083.2 \pm 1667.2$ & $1247.8 \pm 1399.1$ & $742.9 \pm 804.3$ & $955.1 \pm 958.0$ & $1172.4 \pm 1361.4$ \\
\hline$\beta$-carotene (ug) & & $3648.6 \pm 3546.3$ & $4115.4 \pm 3647.8$ & $4671.7 \pm 3971.7$ & $3159.7 \pm 2240.2$ & $5128.2 \pm 3987.8$ & $5974.7 \pm 4992.3$ \\
\hline Cryptoxanthin (ug) & & $125.5 \pm 112.4$ & $141.6 \pm 129.5$ & $122.0 \pm 102.0$ & $122.0 \pm 113.3$ & $125.6 \pm 130.6$ & $86.2 \pm 80.5$ \\
\hline Lutein (ug) & & $1552.5 \pm 1453.3$ & $1467.5 \pm 1366.6$ & $2168.4 \pm 2502.7$ & $1411.7 \pm 1448.0$ & $2932.5 \pm 3260.3$ & $3934.2 \pm 4599.6$ \\
\hline Lycopene (ug) & & $6584.8 \pm 6388.1$ & $4064.8 \pm 3339.9$ & $5850.4 \pm 3981.4$ & $6145.7 \pm 5059.1$ & $5015.8 \pm 3093.1$ & $5797.7 \pm 4864.8$ \\
\hline
\end{tabular}

*Recommended Dietary Allowance or Adequate Intake value for men age 19 - 30 years.

Values are means \pm SD.

[21]. Moreover, using the FFQ allowed investigation of the absolute, unadjusted levels of micronutrient intakes, and thus, how much of each micronutrient subjects consumed (i.e., in milli- or micrograms). By doing so, comparison to the Dietary Reference Intakes was performed, as opposed to assessing only percentages or percentiles of intakes [50]. The other strengths of this study are the consistency of data collection methodology over several years and the assessment of important dietary factors that have not been previously reported in this population.

\section{CONCLUSIONS}

This is the first comparison of the specific micronutrient intakes of students enrolled in a US medical school to the Dietary Reference Intake values. The main finding 
was that dietary intakes were especially low in male and female students for key nutrients related to maintaining health and preventing chronic disease, that is, folate, vitamin $\mathrm{D}$, vitamin $\mathrm{E}$, calcium, magnesium, potassium and iron. Insufficient dietary intakes for these specific nutrients were consistent across all students in all years and lower than demographically-matched population-based data [51,52]. It is notable that only $25 \%$ of males and $22 \%$ of females reported consuming more than 2 servings of fruits per day. Likewise, only $23 \%$ of males and $19 \%$ of females reported consuming 3 or more servings of milk and dairy products per day. Even with the increased number of daily vegetable servings observed in female cohorts across the six years, vegetable intakes did not meet most recent guidelines which suggest consuming twice as many vegetable servings as previously recommended to achieve adequate intakes of the variety of vitamins, minerals and other micronutrients necessary for maintaining health [44].

Inadequate or excessive intakes of micronutrients can lead to various disorders. For one example, vitamin D deficiency combined with inadequate calcium intakes predisposes persons to demineralization of the skeleton which leads to osteomalacia, bone loss, osteopenia and/ or osteoporosis [53]. In addition to bone health, vitamin $\mathrm{D}$ may also have a role in risk for certain types of cancer and type 2 diabetes. For another example, iron, folate and vitamin B12 cause varying forms of anemia [54]. While the occurrence of macrocytic anemia from folate or vitamin B12 deficiency is rarer than iron deficiency anemia, folate intake is also crucial for prevention of neural tube defects, a serious consideration for women of reproductive age, such as those studied herein. Other functions of suboptimal B vitamin intake, including the role on plasma homocysteine concentration and development of cardiovascular disease continue to be investigated. Moreover, inadequate micronutrient intake (ie, vitamin $\mathrm{A}$, vitamin $\mathrm{D}$, the $\mathrm{B}$ vitamins, calcium, iron and zinc) may be associated with increased adiposity, a major public health concern as obesity is epidemic worldwide [55].

The reasons for the micronutrient inadequacies identified herein are likely multi-factorial and may include the significant time constraints inherent in the medical school environment [56], the high level of stress in that environment that has the potential to affect appetite and eating behaviors [57], financial considerations that may influence food purchasing patterns [58], as well as perceptions of body image that may limit the quantity of foods consumed [59]. Clearly, further investigation is warranted to elucidate the determinants of the dietary practices of medical students, as well as other health care professionals.

Nevertheless, the findings from this study may be used to design practical interventions for medical student populations to help them improve their dietary intakes, especially to improve the balance of micronutrients consumed, which may serve to reduce risk for development of chronic disease in these young adults. These data may also be used to enhance the nutrition education content of the medical school curriculum, possibly using publicly available tools such as those produced under the Nutrition Academic Award Program [17]. Ultimately, the goal is to stimulate greater awareness among medical students of their dietary intakes - not only to identify their personal dietary imbalances, and thus, improve their food selection choices to better meet public dietary recommendations, but also to enhance their preparedness as future healthcare providers so they are better able to identify and meet the nutrition needs of their patients.

\section{ACKNOWLEDGEMENTS}

The authors thank Charles D. Keil and Jessica Landsgesell, RD for assistance with data analysis and manuscript preparation.

\section{REFERENCES}

[1] US Department of Health and Human Services. http://health.gov/dietaryguidelines/2010.asp

[2] Frank, E., Galuska, D., Elon, L. and Wright, E. (2004) Personal and clinical exercise-related attitudes and behaviors of freshmen US medical students. Research Quarterly for Exercise \& Sport, 75, 112-121.

[3] Frank, E. (2004) Physician health and patient care. The Journal of the American Medical Association, 291, 637. doi:10.1001/jama.291.5.637

[4] Frank, E., Rothenberg, R., Lewis, C. and Belodoff, B.F. (2000) Correlates of physicians' prevention-related practices Findings from the Women Physicians' Health Study. Archives of Family Medicine, 9, 359-367. doi:10.1001/archfami.9.4.359

[5] Frank, E., Wright, E.H., Serdula, M.K., Elon, L.K. and Baldwin, G. (2002) US women physicians' personal and clinical nutrition-related practices. The American Journal of Clinical Nutrition, 75, 326-332.

[6] Spencer, E.H., Frank, E., Elon, L.K., Hertzberg, V.S., Galuska, D. and Serdula, M.K. (2006) Predictors of nutrition counseling behaviors and attitudes among US medical students. The American Journal of Clinical Nutrition, 84 655-662.

[7] Frank, E., Breyan, J. and Elon, L. (2000) Physician disclosure of healthy personal behaviors improves credibility and ability to motivate. Archives of Family Medicine, $\mathbf{9}$, 287-290. doi:10.1001/archfami.9.3.287

[8] Podell, R.N., Gary, L.R. and Keller, K. (1975) A profile of clinical nutrition knowledge among physicians and medical students. Journal of Medical Education, 50, 888892.

[9] Phillips, M.G. (1971) The nutrition knowledge of medical 
students. Journal of Medical Education, 46, 86-90.

[10] Mlodinow, S.G. and Barrett-Connor, E. (1989) Physicians' and medical students' knowledge of nutrition. Academic Medicine, 64, 105-106. doi:10.1097/00001888-198902000-00017

[11] Davis, C.H. (1994) The report to Congress on the appropriate federal role in assuring access by medical students, residents, and practicing physicians to adequate training in nutrition. Public Health Report, 109, 824-826.

[12] Conroy, M.B., Delichatsios, H.K., Hafler, J.P. and Rigotti, N.A. (2004) Impact of a preventive medicine and nutriation curriculum for medical students. The American Journal of Preventive Medicine, 27, 77-80. doi:10.1016/i.amepre.2004.03.009

[13] Talip, W.A., Steyn, N.P., Visser, M., Charlton, K.E. and Temple, N. (2003) Development and validation of a knowledge test for health professionals regarding lifestyle modification. Nutrition, 19, 760-766. doi:10.1016/S0899-9007(03)00101-1

[14] Frankle, R.T., Williams, E.R. and Christakis, G. (1972) Nutrition education in the medical school: Experience with an elective course for first-year medical students. The American Journal of Clinical Nutrition, 25, 709-719.

[15] Thomson, C.A., Taren, D., Koff, N., Marian, M., Canfield, L., Bassford, T. and Ritenbaugh, C. (2000) An integrated nutrition curriculum in medical education. Journal of Cancer Education, 15, 127-129.

[16] Ammerman, A., McGaghie, W.C., Siscovick, D.S., Maxwell, K., Cogburn, W.E. and Simpson, R.J. Jr. (1989) Medical students' knowledge, attitudes, and behavior concerning diet and heart disease. The American Journal of Preventive Medicine, 5, 271-278.

[17] Van Horn, L. (2006) The nutrition academic award: Brief history, overview and legacy. The American Journal of Clinical Nutrition, 83, 936S-40S.

[18] Wong, V., Millen, B.E., Geller, A.C., Rogers, A.E., Maury, J.J. and Prout, M.N. (2004) What's in store for medical students? Awareness and utilization of expert nutrition guidelines among medical school preceptors. Preventive Medicine, 239, 753-759. doi:10.1016/j.ypmed.2004.02.046

[19] Mellen, P.B., Palla, S.L., Goff, D.C. Jr. and Bonds, D.E. (2000) Prevalence of nutrition and exercise counseling for patients with hypertension. United States, 1999 to 2000. Journal of General Internal Medicine, 19, 917-924. doi:10.1111/j.1525-1497.2004.30355.x

[20] Heimburger, D.C., Ullmann, D.O., Ramsey, M.J., Wooldridge, N.H., Epps, L.A., Hardin, J.M. and Hsu, C. (1994) Dietary habits of first-year medical students assessed during clinical nutrition course. Nutrition, 10, 214-220.

[21] Banks, W.L. Jr., Chan, W.M. and Williams, W.L. (1989) Use of food frequency questionnaire results to emphasize nutritional concepts for first year medical students - Medical College of Virginia. Bulletin of the New York Academy of Medicine, 65, 928-934.

[22] Spencer, E.H., Elon, L.K., Hertzberg, V.S., Stein, A.D. and Frank, E. (2005) Validation of a brief diet survey instrument among medical students. Journal of the Ameri- can Dietetic Association, 105, 802-806. doi:10.1016/j.jada.2005.02.003

[23] US Department of Health and Human Services (2010) Dietary Guidelines for Americans. Office of Disease Prevention and Health Promotion. http://health.gov/dietaryguidelines/2010.asp

[24] Holick, M.F. (2004) Vitamin D: Importance in the prevention of cancers, type 1 diabetes, heart disease, and osteoporosis. The American Journal of Clinical Nutrition, 79, 362-371.

[25] Bakhireva, L.N., Barrett-Connor, E., Kritz-Silverstein, D. and Morton, D.J. (2004) Modifiable predictors of bone loss in older men: A prospective study. The American Journal of Preventive Medicine, 6, 436-442. doi:10.1016/j.amepre.2004.02.013

[26] Centers for Disease Control and Prevention (1991) Use of folic acid for prevention of spina bifida and other neural tube defects: 1983-1991. Morbidity and Mortality Weekly Report, 30, 513-516.

[27] Blot, I., Papiernik, E., Kaltwasser, J.P., Werner, E. and Tchernia, G. (1981) Influence of routine administration of folic acid and iron during pregnancy. Gynecologic and Obstetric Investigation, 6, 294-304. doi: $10.1159 / 000299659$

[28] Krishna, G.G. and Kapoor, S.C. (1991) Potassium depletion exacerbates essential hypertension. Annals of Internal Medicine, 115, 77-83.

[29] Coruzzi, P., Brambilla, L., Brambilla, V., et al. (2001) Potassium depletion and salt sensitivity in essential hypertension. The Journal of Clinical Endocrinology \& Metabolism, 86, 2857-2562. doi:10.1210/jc.86.6.2857

[30] Sommer, A. and West, K.P. Jr. (1996) Vitamin A deficiency: Health, survival and vision. Oxford University Press, New York.

[31] Dawson, H.D. and Ross, A.C. (1999) Chronic marginal vitamin A status effects the distribution and function of $\mathrm{T}$ cells and natural $\mathrm{T}$ cells in aging Lewis rats. Journal of Nutrition, 129, 1782-1790.

[32] Stephensen, C.B. (2001) Vitamin A, infection and immune function. The Annual Review of Nutrition, 21, 167-192. doi:10.1146/annurev.nutr.21.1.167

[33] Mocchegiani, E., Giacconi, R., Muzzioli, M. and Cipriano, C. (2000) Zinc, infections and immunosenescence. Mechanisms of Ageing and Development, 121, 21-35. doi:10.1016/S0047-6374(00)00194-9

[34] Wintergerst, E.S., Maggini, S. and Hornig, D.H. (2006) Immune-enhancing role of vitamin $\mathrm{C}$ and zinc and effect on clinical condition. Annals of Nutrition and Metabolism, 50, 85-94. doi:10.1159/000090495

[35] Selhub, J., Jacques, P.F., Wilson, P.W., Rush, D. and Rosenberg, I.H. (1993) Vitamin status and intake as primary determinants of homocysteinemia in an elderly population. The Journal of the American Medical Association, 270, 2693-2698. doi:10.1001/jama.1993.03510220049033

[36] Ali, M.M. and Vaidya, R.R. (2007) Vitamin D and cancer. Journal of Cancer Research, 4, 225-230. doi:10.4103/0973-1482.38998 
[37] White, E., Shannon, J.S. and Patterson, R.E. (1997) Relationship between vitamin and calcium supplement use and colon cancer. Cancer Epidemiology, Biomarkers \& Prevention, 6, 769-774.

[38] Kampman, E., Slattery, M.L., Caan, B. and Potter, J.D. (2000) Calcium, vitamin D, sunshine exposure, dairy products and colon cancer risk (United States). Cancer Causes Control, 11, 459-466. doi:10.1023/A:1008914108739

[39] Block, G., Hartman, A.M. and Naughton, D. (1990) A reduced dietary questionnaire: Development and validation. Epidemiology, 1, 58-64. doi:10.1097/00001648-199001000-00013

[40] United States Department of Agriculture (2000) Agricultural Research Service. Nutrient Data Laboratory. http://www.ars.usda.gov/nutrientdata/

[41] Institute of Medicine (2005) Food and Nutrition Board. The dietary reference intakes for energy, carbohydrates, fiber, fat, protein and amino acids (macronutrients). National Academies Press, Washington DC.

[42] Institute of Medicine (2000) Food and Nutrition Board. Dietary reference intakes: Applications in dietary assessment. National Academies Press, Washington DC.

[43] United States Department of Agriculture. http://www.mypyramid.gov/

[44] Britten, P., Marcoe, K., Yamini, S. and Davis, C. (2006) Development of food intake patterns for the MyPyramid food guidance system, Journal of Nutrition Education and Behavior, 38, S78-S92. doi:10.1016/i.jneb.2006.08.007

[45] Mitchell, D.C., Frank, L.R., Hartman, T.J. and Curran, J.M. (2009) Consumption of dry beans, peas, and lentils could improve diet quality in the US population. Journal of the American Dietetic Association, 109, 909-913. doi:10.1016/j.jada.2009.02.029

[46] American Dietetic Association (2000) Position of the American Dietetic Association: Fortification and nutriational supplements. Journal of the American Dietetic Association, 105, 1300-1311.

[47] Spencer, E.H., Bendich, A. and Frank, E. (2006) Vitamin and mineral supplement use among US medical students: A longitudinal study. Journal of the American Dietetic Association, 106, 1975-1983. doi:10.1016/j.jada.2006.09.003

[48] Frank, E., Carrera, J.S., Elon, L. and Herzberg, V.S. (2006) Basic demographics, health practices, and health status of
US medical students. The American Journal of Preventive Medicine, 31, 499-505. doi:10.1016/j.amepre.2006.08.009

[49] Subar, A.F., Kipnis, V., Troiano, R.P., et al. (2003) Using intake biomarkers to evaluate the extent of dietary misreporting in a large sample of adults: The OPEN study. American Journal of Epidemiology, 158, 1-13. doi:10.1093/aje/kwg092

[50] Block, G. (2000) Invited commentary: Another perspective on food frequency questionnaires. American Journal of Epidemiology, 154, 1103-1104. doi:10.1093/aje/154.12.1103

[51] Wakimoto, P. and Block, G. (2001) Dietary intake, dietary patterns, and changes with age: An epidemiological perspective. The Journals of Gerontology: Series A, 56, 6580.

[52] US Department of Agriculture and US Department of Health and Human Services (2000) What we eat in America, NHANES 2007-2008.

[53] Chung, M., Balk, E.M., Brendel, M., Ip, S., Lau, J., Lee, J., et al. (2009) Vitamin D and calcium: Systematic review of health outcomes. Agency for Healthcare Research and Quality, Rockville.

[54] Selhub, J. and Paul, L. (2011) Folic acid fortification: Why not vitamin B12 also? Biofactors, 37, 269-271. doi:10.1002/biof.173

[55] Garcia, O.P., Long, K.Z. and Rosado, J.L. (2009) Impact of micronutrient deficiencies on obesity. Nutrition Reviews, 67, 559-572. doi:10.1111/j.1753-4887.2009.00228.x

[56] Mothersbaugh, D.L., Hermann, R.O. and Warland, RH. (1993) Perceived time pressure and recommended dietary practices: The moderating effect of knowledge of nutrition. Journal of Consumer Affairs, 27, 106-126. doi:10.1111/j.1745-6606.1993.tb00740.x

[57] Dyrbye, L.N., Thomas, M.R. and Shanafelt, T.D. (2006) Systematic review of depression, anxiety, and other indicators of psychological distress among US and Canadian medical students. Academic Medicine, 81, 354-373. doi:10.1097/00001888-200604000-00009

[58] Drewnowski, A. and Darmon, N. (2005) Food choices and diet costs: An economic analysis. Journal of Nutrition, 135, 900-904.

[59] Futch, L.S., Wingard, D.L. and Felice, M.E. (1988) Eating pattern disturbances among women medical and graduate students. Journal of Adolescent Health, 9, 378-383. doi:10.1016/0197-0070(88)90032-0 